\title{
Student-related factors affecting academic engagement: A qualitative study exploring the experiences of Iranian undergraduate nursing students
}

\author{
Mohammad Reza Ghasemi ${ }^{1}$, Hossein Karimi Moonaghi ${ }^{2,3}$, Abbas Heydari ${ }^{2,3}$
}

${ }^{1} \mathrm{PhD}$ Candidate in Nursing, Department of Medical-Surgical Nursing, School of Nursing and Midwifery, Mashhad University of Medical Sciences, Mashhad, Iran

${ }^{2}$ Evidence-Based Care Research Center, Mashhad University of Medical Sciences, Mashhad, Iran

${ }^{3}$ Department of Medical-Surgical Nursing, School of Nursing and Midwifery, Mashhad University of Medical Sciences, Mashhad, Iran

\section{Type of article: Original}

\begin{abstract}
Background and aim: Academic engagement is an important indicator of quality of higher education. This study aimed to explain the experiences of undergraduate nursing students in terms of student-related factors affecting academic engagement.

Methods: This qualitative study was conducted in 2017 at Mashhad University of Medical Sciences in Iran. Data were collected using semi-structured interviews and focus groups with 7 and 16 undergraduate nursing students at Mashhad School of Nursing and Midwifery; respectively. Undergraduate nursing students of both genders who enrolled in different academic semesters with various academic achievements were selected. Data were analyzed using conventional content analysis approach proposed by Graneheim and Lundman, with the support of MAXQDA software.

Results: After analyzing the data, 374 initial codes were extracted, which ultimately conceptualized within six main categories including: "learning motivation", "interest in learning", "student participation in extracurricular scientific programs", "self-directedness", "mental concentration", and "demonstration of emotions".

Conclusion: The findings of this study indicated that student-related factors such as individual motivation and interest, mental concentration, participation in extracurricular activities, and self-directedness in learning, as well as students' sense of satisfaction with learning could play important roles in the creation of academic engagement in undergraduate nursing students that need to be of interest to nursing educators and planners.
\end{abstract}

Keywords: Academic success; Engagement, Students, Nursing; Learning, Qualitative research

\section{Introduction}

One of the major challenges faced by faculty is to draw learners' attention to educational contents and to help with their learning, which is named academic engagement (1-2). Academic engagement can be defined as efforts devoted by students to academic activities. It is a result of dynamic interactions between students, educators, academic activities, as well as educational conditions and environments (3). It is recognized as a significant indicator of quality of higher education (4-5). Lack of academic engagement can lead to unfavorable outcomes such as low academic achievement, incivility, increased risk of failure and dropout (6). The quality of nursing care, which is rooted in nurses' professional competencies, ensures the preservation, promotion, and rehabilitation of patients and clients. The basis of acquiring scientific and practical skills of nurses is placed in their educational course in

\section{Corresponding author:}

Dr. Hossein Karimi Moonaghi, School of Nursing and Midwifery, Mashhad University of Medical Sciences, EbneSina Street, Mashhad, Iran. Tel: +98.5138511511, Fax:+98.513859-07313, Email: karimih@mums.ac.ir

Received: January 24, 2018, Accepted: April 25, 2018, Published: July 2018

iThenticate screening: April 26, 2018, English editing: May 04, 2018, Quality control: June 12, 2018

This article has been reviewed / commented by six experts

Ethics approval: IR.MUMS.REC.1395.121 (Mashhad University of Medical Sciences)

Funding approval: 9244 (Mashhad University of Medical Sciences)

Research project approval: 941223 (Mashhad University of Medical Sciences)

(C) 2018 The Authors. This is an open access article under the terms of the Creative Commons Attribution-NonCommercialNoDerivs License, which permits use and distribution in any medium, provided the original work is properly cited, the use is non-commercial and no modifications or adaptations are made. 
academic settings; therefore, the learning activities, which student nurses perform in their academic courses, can play important roles in shaping future professional capabilities (7). Among the various important factors involved in learning and success of students are willpower and motivation by students, and consequently, their serious engagement in learning process (8). However, findings from previous studies indicated relatively low or moderate levels of academic engagement among nursing students (1). Thus, teachers and educational planners are recommended to pay special attention to this issue and develop educational strategies to improve students' academic engagement. One of the fundamental measures to help nursing students achieve academic success and better academic performance and consequently gain ability to provide high-quality nursing cares is increasing their academic engagement during their academic years (1). However, the phenomenon of academic engagement is known as a sophisticated, multifaceted, dynamic, condition-dependent phenomenon, which cannot be completely examined quantitatively. As a result, qualitative studies can be employed to explain this issue in an in-depth and more thorough manner $(1,9)$. Given that the role of nursing students in the occurrence of academic engagement has not been deeply examined, this study, therefore, aimed to explore the experiences of undergraduate nursing students regarding student-related factors affecting their academic engagement.

\section{Material and Methods}

\subsection{Research design}

This study using a qualitative research method with a conventional content analysis approach was conducted in 2017 at the School of Nursing and Midwifery affiliated to Mashhad University of Medical Sciences, Iran. Qualitative research methods seek to discover and understand the inner world of individuals, and since experiences can create the structure of the truth for each individual, researchers can only explore the phenomenon by entering into the world of individuals' experiences and from their points of view (10). Therefore, the explanation of this phenomenon was considered in this study through this method as well as an in-depth examination of experiences and behaviors in the real world of people.

\subsection{Inclusion criteria}

The inclusion criteria in this study were being enrolled in an undergraduate nursing course, passing at least one academic semester, and willingness and readiness to participate in the study and to spell out their experiences. Thus, the samples were selected using purposive sampling method.

\subsection{Interviews and data collection}

To collect the data, semi-structured individual interviews and focus groups were used. A focus group is considered as a variety of qualitative studies as well as data collection methods. It comprises of a group of people with common characteristics and experiences wherein researchers proceed to conduct interviews to extract the beliefs, thoughts, and perceptions of members on a particular topic of interest. The ultimate goal for the researcher in this respect is to gain a deep knowledge of how the participants understand the facts based on their shared experiences of the subject matter of the research (10). Participants in this study included undergraduate nursing students enrolled in different academic semesters with various academic achievements of both genders. The researcher contacted the participants via telephone after coordination with the school authorities and students. Before the interviews were initiated, the purpose of the study was shared with the participants. If the students were ready for the interviews, written consent was obtained from them. At first, seven students participated in a semi-structured interview, and then 16 other students were divided in terms of gender, into two focus groups equally. The interviews began with general questions on the subject; then, they were guided by the objectives of the study based on the participants' responses. Examples of the questions raised in the interviews were; "What do you do to learn theoretical and practical lessons?", "What factors lead you to make more efforts for learning?", "What factors or conditions help you better learn the educational contents?", and "What time do you try to learn more or less?". In the process of the interviews, probing questions were asked for a more in-depth study of the participants.

\subsection{Analyses}

Sampling continued to reach data saturation, meaning that no new information was provided by the participants during interviews. Simultaneously, data analysis was performed using conventional content analysis approach as proposed by Graneheim and Lundman (11). They have suggested five steps for analyzing qualitative data: 1. transcribing the entire interview immediately after its implementation, 2. reading the entire interview transcription to get a complete overview of its contents, 3 . determining semantic units and initial codes, 4 . grouping the same initial codes into more comprehensive categories; and 5. determining the latent content in data (11). Interviews were immediately audio-recorded, transcribed verbatim and proofread by the first author for several times and 
consequently, the main codes were extracted. Similar codes were grouped under certain categories by using the constant comparative analysis. To ensure the rigor of the study, the trustworthiness criteria including credibility, transferability, confirmability, and dependability were used (12). In order to maximize the diversity of the participants, they were selected from various students in terms of semester, residence in dormitories or living with family, marital status, grade point average, and gender.

\subsection{Ethics of research}

This research project was approved by the ethics committee of Mashhad University of Medical Sciences (Ref: IR.MUMS.REC.1395.121). For ethical considerations, the research objectives and methodology were explained and then informed consent was obtained from participants. Furthermore, all the interviews were audio taped with the consent of the participants.

\section{Results}

The study participants included 10 female and 13 male undergraduate nursing students with the mean age of 23 years. They were in different academic semesters from the second to the eighth semesters with a mean grade point average of 16.86. Of the participants, seven individuals were married and the rest were single, five of them lived with their family and the others resided in dormitories. To obtain the data, seven individual interviews and two focus groups were conducted considering participants' gender. The duration of each interview was between 65-110 minutes and the time of the focus groups were about 90 minutes. After data analysis, 374 initial codes were extracted and the data were analyzed into six main categories of "learning motivation", "interest in learning", "student participation in extracurricular scientific programs", "self-directedness", "mental concentration", as well as "demonstration of emotions". Table 1 illustrated the relationship between the subcategories and the main categories.

Table 1. The relationship between the subcategories and the main categories

\begin{tabular}{|l|l|}
\hline Main category & Subcategory \\
\hline \multirow{4}{*}{ Learning motivation } & Learning motivations for theory lessons \\
\cline { 2 - 2 } & Learning motivations for clinical skills \\
\cline { 2 - 2 } & No motivation among students \\
\hline \multirow{4}{*}{$\begin{array}{l}\text { Interest in learning } \\
\text { committees }\end{array}$} & Interest in subject contents \\
\cline { 2 - 2 } & Attractive teaching styles making students interested in learning \\
\cline { 2 - 2 } & Previous familiarity with educational contents \\
\hline \multirow{5}{*}{ Self-directedness } & Engagement with extracurricular scientific activities \\
\cline { 2 - 2 } & Participation in student science committees \\
\hline \multirow{5}{*}{ Mental concentration } & Attempting to learn nursing skills \\
\cline { 2 - 2 } & Search skills in different resources \\
\cline { 2 - 2 } & Using multimedia learning \\
\cline { 2 - 2 } & Summarizing skills from lessons \\
\hline Demonstration of emotions & Active attendance in classrooms \\
\cline { 2 - 2 } & No mental concentration in classrooms \\
\cline { 2 - 2 } & Sense of satisfaction with learning \\
\cline { 2 - 2 } & Dissatisfaction with inadequacy of lessons learned in clinical practice \\
\cline { 2 - 2 } & Pleasure of teaching and learning from peers \\
\hline
\end{tabular}

\subsection{Learning Motivation}

Participants' experiences showed that individual motivation as an internal factor could increase students' academic engagement by stimulating the learning of theory lessons and acquiring clinical skills. Students consider learning theory lessons as the core for better learning of practical skills. A participant said, “... learning the theory lessons could make it easier to understand practical work both in the clinical skill lab and the hospital. For example, I studied the theory lessons of heart disease; then, when I started the internship, I found these contents very useful and contributing to the provision of care for patients; because of this, I am trying to learn more about these lessons ..." (nurse student, male, eighth semester). Another motivating factor was scientific discussion atmosphere in classrooms. Those discussions would encourage learners to pay more attention to the content of lessons and encourage them to study and to engage in discussions further. A third-semester nursing student stated, "... in some lessons wherein the teachers asked questions in the classrooms or proposed an issue for discussion, the students were encouraged to contribute more to the discussions. I myself even review previous lessons and study about new 
lessons to have a chance to participate in discussion. In this way, I can study more and learn better ...". One of the factors provoking the learning of practical skills was attention to the importance of patient care. To have the abilities to preserve a patient's life, nursing students need to acquire the necessary skills to provide critical nursing care. A female fourth semester student nurse said,“... in nursing work, proper care can sometimes save a patient's life; so I am trying very hard to practice nursing effectively and learn how to work properly in a hospital whenever it is needed...”. The other factor encouraging participants to learn practical skills was the practical nature of the nursing profession. Learning nursing skills is considered as the main feature of this profession. Accordingly, a female thirdsemester nursing student shed light on the need to learn nursing skills and said,“... when I went to the hospital for the internship, I realized that in addition to theoretical lessons, remembering practical nursing work was very important, so I tried to learn practical nursing better ...". Analyzing the data revealed that low or lack of motivation as an internal factor could reduce the educational efforts and activities in students. Lack of motivation could lead to a reduction in students' academic engagement. One of the issues causing students not to be motivated to learn the subjects is lack of using theory lessons in clinical practice. A participant said, "... when I went to work as an intern, I found that much of what had been presented in classrooms was not of use in hospital at all...". Moreover, analysis of the data suggested that the other factor inducing students to be indifferent was an inappropriate social vision towards the nursing profession. A male nursing student of the fifth semester added, “... when you see that nursing is unknown within the social community and it does not stand by itself, you have no motivation to make efforts in this field ..."

\subsection{Interest in Learning}

Participants' experiences demonstrated that interest in learning was one of the factors increasing academic engagement in nursing students. Among factors influencing interest in learning, was students' appeal towards subjects or educational contents. Interest can also provide intellectual and mental concentration on educational subjects, increase learning efforts, and ultimately lead to a greater and deeper learning. A seventh-semester male participant said, “... if I liked the subjects taught by some teachers, I used to study them more and more. For example, I was interested in the heart; so I used to spend more time on it and studied it further...". Teaching methods could raise interest in the students to learn more. Applying new teaching methods along with the expression of clinical experiences and student participation could have a major contribution to students' interest in learning educational contents of the course and increase their academic engagement. A seventh-semester female nurse student stated, ".. one of the educators was endowed with good teaching methods; he also provided good clinical examples for theory lessons and made it easy to understand the contents. Besides this, he repeatedly raised interesting clinical questions during the lessons. These made me become more interested in lessons and also made me more active in learning such contents ...". Participants' experiences showed that prior knowledge about the teaching subject could be considered as another factor that would interest students in learning. A fifth-semester male nurse student added, “... some teachers provided us with the educational materials, and asked us to study them for the next sessions. As I studied those materials, I became more interested in the educational contents of next session ..."

\subsection{Participation in extracurricular scientific activities}

Our analysis reflected that students' participation in extracurricular scientific activities could indirectly increase their professional awareness and capabilities. For example, participating in English language lessons as well as being a member of student associations could also increase students' academic interactions. The development of scientific interactions between students could also lead to learning from peers as well as promotion of knowledge and professional skills in nursing students. A fifth-semester female participant expressed, "... after I became a member of the student research committee, I participated at several workshops and learned many useful lessons, which help me get through when I came up with a question or a problem in nursing lessons or internship..." Based on the participants' experiences, membership in scientific associations of nursing students could increase students' relationships and academic interactions with each other. In addition, activities in student scientific associations could allow them to learn from their peers. A sixth-semester female nurse student said, "... I became more familiar with nursing students enrolled in other semesters in this nursing academic association. In the discussion forums, academic nursing science topics were discussed; in this way, I could learn a lot from students of higher semesters and I tried to learn more. Sometimes I have to present a topic for discussion. This stimulates me to make even more efforts to learn ..." 


\subsection{Self-Directedness}

Self-directedness in learning can result in lifelong learning. One of the aspects of self-directedness in learning is students' efforts and planning for learning. Data analysis showed that nursing students were planning to learn better and more effectively in clinical skills at the time of training in the center for clinical skills. Nursing students also gave more value and importance to the learning of nursing skills compared with theory lessons. A second-semester male student stated,“... since correctly doing practical things is important to patients, in the practice room, I listen and look very well to everything presented by the teacher, and also practice very well ..." Self-directed students can identify and address their own educational needs without being in a formal education system. Students' experiences revealed that they could meet a part of their educational needs by searching in various sources. Moreover, selfdirected students could use their creativity to learn better. To facilitate their learning, some nursing students made various media files such as recording the teacher's voice and filming clinical skills and converting them to pamphlets. A fourth-semester female student stated, “... I was taking my internship in the injection unit; I found that the medicine was blocked on the needle when I was doing an intramuscular injection of penicillin. The teacher had not talked about this problem and what to do to solve it. So, I searched in different sites, I looked at books on the principles of nursing techniques, and I realized that changing the needle or draining a little distilled water into the syringe before the injection could prevent this problem ..... A second-semester male nursing student added, “... in order to have good sources for studying the theory lessons in the classroom, we decided to make audio files from class sessions for some important lessons, and then we transcribed these files together and made a pamphlet. We got good grades ...". Self-directed students could improve their learning by acquiring various learning skills, including note-taking skills in the classroom and during their study. Acquiring proper study learning skills, nursing students could self-direct and increase their efforts to learn better. A sixth-semester nursing student stated, ".... to understand the contents better; I firstly note down the materials and secondly, I write down important points to review quickly later. This helps me to have good sources for study during my exams and to get better grades ..."

\subsection{Mental Concentration}

Participants' experiences indicated that one of the factors influencing their learning was mental and intellectual concentration on theoretical and practical teaching contents. Considering that the prerequisite for learning intellectual and mental contents is to focus on educational materials, such concentration on educational contents can promote academic engagement. Therefore, it can be said that one of the components of academic engagement is intellectual and mental concentration on educational contents as well as active participation of students in the classroom. Activities such as answering questions and commenting on the topic under discussion are indicators of active participation in the classroom. Considering note-taking in the classroom, focusing on teacher talks, and participating actively in classrooms; one of the sixth-semester male participants stated, “... during all the classes when the teacher starts the lessons or even during the internship, I do not write anything down, I always listen carefully because I think that listening and concentrating are much more effective for me. Because I pay attention to the teaching subject, I sometimes ask questions from the teacher when I come up with them, and I participate in classroom discussions. These make me learn more ...". One of the challenges faced by many teachers in the classroom is lack of attention and concentration by learners on the subject of the lessons and courses. Some nursing students also participated passively in the classrooms for a variety of reasons, including lack of motivation for learning or mandatory attendance in the classroom, so they did not pay attention to the subject of the lessons, which could reduce their academic engagement and learning. A seventh-semester male student said, “... I do attend most classes just because I do not like to be an absentee, so I do not pay attention to the lessons in the classroom presented by teachers. I do not learn much in the classrooms; I only study at exam times to get the passing grades ..."

\subsection{Demonstration of Emotions}

Learning can lead to students' academic achievement and increase their satisfaction with learning activities. Such a sense of satisfaction can encourage students to be more active. Satisfaction with learning also increases student engagement in education and training. Our analysis showed that students' satisfaction with learning could increase their efforts for more learning. In this regard, a fifth-semester male nursing student stated, "... I was practicing on patients the theory lessons I learned. It increased my self-confidence. It also made me more enthusiastic to attend the internship and to study more. Thus, I became encouraged to study more and I feel satisfied now ...”. In contrast, dissatisfaction with non-application of learning theory lessons in clinical practice could lead to students' lack of consent and make them reduce their efforts to learn more. Besides this, dissatisfaction from learning activities could lower learning efforts and reduce academic engagement. A seventh-semester female nurse student added, “... I used to study lessons such as diagnostic tests, pharmacology, clinical procedures in advance; then, I realized that they were useless in practice; doctors did not allow us to do anything, and we could not do something. I mean it was not 
useful, so I decided not to study them any more ....'. Students' experiences suggested that unavailability of clinical opportunities for nursing students to practice the learned theories could bring about dissatisfaction and reduce learning activities as well as their academic engagement. An eighth-semester male nursing student stated, “... before I start the CCU internship, I used to study so much about dysrhythmias and ECG and their interpretations with lots of interest, but I saw that we just needed to administer medicine. The personnel were doing the same. Well, when I found that knowing and interpreting the ECG was not useful for us, I asked myself, why I was doing so. They had no use in clinical applications, so I cut my studies ...". Teaching peers and learning from peers are considered as student-centered learning approaches. Within their experiences, the nursing students acknowledged that learning from classmates was very appealing to them and it could similarly lead to learning that is more effective. A sixthsemester female nursing student explained, “... we decided in the classroom to learn the hardest and the most important lessons with the help of each other. To this end, each student had to study the contents and then we discussed them. In this way, the students who had studied the contents better from different sources and understood them could help the rest of students to realize the contents better with their own explanations. So, we could have more additional activities, we could also learn better, and we felt satisfied with each other ..."

\section{Discussion}

The findings of the present study revealed that the student-related factors playing important roles in academic engagement of nursing students were individual motivation and interest, participation in extracurricular activities, self-directedness, mental concentration, and demonstration of emotions. Motivation and interest had prominent roles influencing learning and academic engagement in nursing students. Previously, it has been suggested that motivations could play an important role in achieving educational goals, give learners energy, and consequently lead to the development of academic behaviors (13-14). In a study in Finland, it was revealed that higher levels of learning motivations of nursing students could be accompanied by higher academic engagement and lower academic burnout (14). It has been demonstrated that internal and external motivational factors can be the predictors of success in teaching nursing care. In addition, motivation was positively associated with learning outcomes, and positive results of learning could be related to increased persistence in teaching nursing (15-16). Therefore, learning motivation can make learning better and increase engagement in nursing students. Moreover, a strong correlation between learning motivation and self-efficacy of nursing students has been established. Accordingly, it has been suggested that nursing students' self-efficacy can be promoted in terms of nursing professional competence by increasing their learning motivation (16). Therefore, increasing the learning motivation of nursing students can improve their self-directedness and thus increase their engagement in academic affairs.

Nursing students believed that participation in extracurricular scientific activities could lead to an increase in their academic and professional abilities. In this respect, a study in Australia found teaching research methods as an extracurricular activity could have a significant impact on evidence-based care research in nursing students (17). It has been also shown that extracurricular activities can increase retention of students in learning environments (18). The findings of the study conducted by Jones et al. shed light on the important and positive role of extracurricular activities in students' academic achievement as well as the relationship between motivation to do extracurricular activities and improve academic performance of students (19). The experiences of nursing students accounted for this issue that educational activities planned and implemented by the students themselves (self-directed learning) were very helpful in learning nursing lessons and skills. In a study aimed to determine the relationship between selfdirected learning readiness and nursing competence among nursing graduates, it was revealed that self-directed learning readiness and nursing competence were positively correlated. In other words, self-directed learning can improve nursing competencies (20). Similarly, the results of a study on medical students showed a significant and positive correlation between self-directed learning and participation in educational workshops (problem-solving skills workshop) during the academic years (21). Moreover, in a research carried out at a US medical center, the results indicated that those participating in a problem-solving skills workshop showed significantly higher selfdirected learning levels than their counterparts did (22). These studies indicated that students' self-directedness could result in conducting effective learning activities.

Students participating in the study acknowledged that subject comprehension and learning could be increased if there was mental concentration. Mental concentration on an educational subject is required for academic engagement. The study conducted by Sulaiman in Malaysia also suggested that focusing on lesson contents could lead to learning and satisfaction with learning in students (23). A study by Hughes et al showed that one of the important factors affecting concentration on lesson contents was interest in the subjects. Furthermore, lack of interest about the subjects was one of the main factors affecting lack of learning and absenteeism in the classrooms 
(24). It should be noted that appeal of the lesson contents and focus on them were among the most important motivators in the classroom (25). Furthermore, the nursing students participating in the study also believed that sense of satisfaction with learning activities could lead them to make more effort and to do more academic activities and consequently increase their academic engagement. In this regard, Walker et al found that satisfaction with learning could result in motivation in students and this would lead to making more effort in this domain. Thus, satisfaction with learning could improve academic engagement of students (26).

\section{Conclusions}

The findings of this study suggested that student-related factors such as individual motivation and interest, mental concentration, participation in extracurricular activities, self-directedness and demonstration of emotions could play important roles in learning and academic engagement among undergraduate nursing students that should be of interest to nursing educators and planners. Therefore, it is recommended that further studies focusing on applying the findings to improve academic engagement in these nursing students be carried out.

\section{Acknowledgments:}

This study is a part of the first author's doctoral dissertation (Ref: 941223). The financial support of the Deputy of Research and Technology at Mashhad University of Medical Sciences is gratefully acknowledged. In addition, the authors wish to thank all the study participants for their tremendous cooperation and support.

\section{Conflict of Interest:}

All authors declare no conflict of interest; no conflict of interest exists for any of the authors associated with the manuscript. The funding organization had no role in the design and conduct of the study, or in the collection, analysis, and interpretation of the data.

\section{Authors' contributions:}

Study conception and design: MRG, HKM, and AH. Acquisition of data: MRG. Interpretation of data: MRG, HKM, and AH. Drafting of the manuscript: MRG, HKM, and AH. Critical revision of the manuscript for important intellectual content: MRG, HKM, and AH.

\section{References:}

1) Oriol X, Amutio A, Mendoza M, Da Costa S, Miranda R. Emotional Creativity as Predictor of Intrinsic Motivation and Academic Engagement in University Students: The Mediating Role of Positive Emotions. Front Psychol. 2016; 7: 1243. doi: 10.3389/fpsyg.2016.01243. PMID: 27610091, PMCID: PMC4996992.

2) Jerome M, Janz KF, Baquero B, Carr LJ. Introducing sit-stand desks increases classroom standing time among university students. Prev Med Rep. 2017; 8: 232-7. doi: 10.1016/j.pmedr.2017.10.019. PMID: 29159019, PMCID: PMC5683670.

3) Clarke J, DiMartino J. A Personal Prescription for Engagement. Principal Leadership. 2004; 4(8): $19-23$.

4) Salamonson Y, Andrew S, Everett B. Academic engagement and disengagement as predictors of performance in pathophysiology among nursing students. Contemp Nurse. 2009; 32(1-2): 123-32. doi: 10.5172/conu.32.1-2.123. PMID: 19697983.

5) Noohi E, Montazeri H, Shokohi M. A Review of the academic engagement of medical students in kerman university of medical sciences, Iran, 2011-2012. Strides in Development of Medical Education. 2015; 12(1)1-9.

6) Noohi E, Abaszadeh A, Maddah SSB. University engagement and collaborative learning in nursing students of Kerman University of Medical Sciences. Iran J Nurs Midwifery Res. 2013; 18(6): 505. PMID: 24554951, PMCID: PMC3917136.

7) Horton K, Tschudin V, Forget A. The value of nursing: a literature review. Nurs Ethics. 2007; 14(6): 71640. doi: 10.1177/0969733007082112. PMID: 17901183.

8) van Uden JM, Ritzen H, Pieters JM. Engaging students: The role of teacher beliefs and interpersonal teacher behavior in fostering student engagement in vocational education. Teaching and Teacher Education. 2014; 37: 21-32. doi: 10.1016/j.tate.2013.08.005.

9) Kahu ER. Framing student engagement in higher education. Studies in Higher Education. 2011; 38(5): 75873. doi: 10.1080/03075079.2011.598505.

10) Al-Busaidi ZQ. Qualitative research and its uses in health care. Sultan Qaboos Univ Med J. 2008; 8(1): 11 9. PMID: 21654952 , PMCID: PMC3087733. 
11) Graneheim UH, Lundman B. Qualitative content analysis in nursing research: concepts, procedures and measures to achieve trustworthiness. Nurse Educ Today. 2004; 24(2): 105-12. doi: 10.1016/j.nedt.2003.10.001. PMID: 14769454.

12) Guba EG. Criteria for assessing the trustworthiness of naturalistic inquiries. Educ Technol Res Dev. 1981; 29(2): 75-91.

13) Kosgeroglu N, Acat MB, Ayranci U, Ozabaci N, Erkal S. An investigation on nursing, midwifery and health care students' learning motivation in Turkey. Nurse Educ Pract. 2009; 9(5): 331-9. doi: 10.1016/j.nepr.2008.07.003. PMID: 18768371.

14) Mäenpää K, Pyhältö K, Järvenoja H, Peltonen J. Nursing students' motivation regulation and its relationship with engagement and burnout. Nord J Nurs Res. 2017. doi: 10.1177/2057158517731719

15) Rose S. Academic success of nursing students: Does motivation matter? Teaching and Learning in Nursing. 2011; 6(4): 181-4. doi: 10.1016/j.teln.2011.05.004.

16) Hassankhani H, Mohajjel AA, Rahmani A, Mohammadpoorfard Z. The relationship between learning motivation and self efficacy among nursing students. Res Dev Med Educ. 2015; 4(1): 97-101. doi: 10.15171/rdme.2015.016.

17) Leach MJ, Hofmeyer A, Bobridge A. The impact of research education on student nurse attitude, skill and uptake of evidence - based practice: a descriptive longitudinal survey. J Clin Nurs. 2016; 25(1-2): 194-203. doi: 10.1111/jocn.13103. PMID: 26769207.

18) Peck SC, Roeser RW, Zarrett N, Eccles JS. Exploring the Roles of Extracurricular Activity Quantity and Quality in the Educational Resilience of Vulnerable Adolescents: Variable- and Pattern-Centered Approaches. J Soc Issues. 2008; 64(1): 135-56. doi: 10.1111/j.1540-4560.2008.00552.x. PMID: 19543445, PMCID: PMC2699299.

19) Jones ML, Rush BR, Elmore RG, White BJ. Level of and motivation for extracurricular activity are associated with academic performance in the veterinary curriculum. J Vet Med Educ. 2014; 41(3): $275-83$. doi: 10.3138/jvme.1213-163R. PMID: 24981424.

20) Yang GF, Jiang XY. Self-directed learning readiness and nursing competency among undergraduate nursing students in Fujian province of China. Int J Nurs Sci. 2014; 1(3): 255-9. doi: 10.1016/j.ijnss.2014.05.021.

21) Shokar GS, Shokar NK, Romero CM, Bulik RJ. Self-directed learning: looking at outcomes with medical students. Fam Med. 2002; 34(3): 197-200. PMID: 11922535.

22) Dinkevich E, Ozuah PO. Self - directed learning activities of paediatric residents. Med Educ. 2003; 37(4): 388-9. doi: 10.1046/j.1365-2923.2003.01459.x. PMID: 12654126.

23) Sulaiman WIW, Mahbob MH, Azlan AA. Learning outside the classroom: Effects on student concentration and interest. Procedia Soc Behav Sci. 2011; 18: 12-7. doi: 10.1016/j.sbspro.2011.05.003.

24) Hughes SJ. Student attendance during college-based lectures: a pilot study. Nurs Stand. 2005; 19(47): 41-9. doi: 10.7748/ns.19.47.41.s52.

25) Gump SE. Keep Students Coming By Keeping Them Interested: Motivatorsfor Class Attendance. College Student Journal. 2004; 38(1): 157.

26) Walker S, Rossi D, Anastasi J, Gray-Ganter G, Tennent R. Indicators of undergraduate nursing students' satisfaction with their learning journey: an integrative review. Nurse Educ Today. 2016; 43: 40-8. doi: 10.1016/j.nedt.2016.04.011. PMID: 27286943. 